\title{
Study of blood lead and semen lead concentrations in male infertility
}

\author{
B C Debnath ${ }^{1}$, M Ibrahim $^{2}$, P Fatima $^{3}$
}

\begin{abstract}
Objective: To evaluate the association of blood and semen lead with male infertility.

Design: It was a case control study carried out in the department of Biochemistry, BSMMU, from January, 2004 to December, 2004.

Subjects: Of 52 male subjects, 26 were infertile with oligospermia and / or asthenospermia. Age matched 26 normospermic subjects with normal standard semen parameters (volume, count, motility and morphology) were selected as controls. None had the history of occupational exposure to lead.

Results: Median values of blood lead were $19.96 \mu \mathrm{g} / \mathrm{dl}$ and $17.68 \mu \mathrm{g} / \mathrm{dl}$ (normal $<25 \mu \mathrm{g} / \mathrm{dl}$ ); semen lead were $29.56 \mu \mathrm{g} / \mathrm{dl}$ and $28.17 \mu \mathrm{g} / \mathrm{dl}$ (normal $15.37 \pm 3.92 \mu \mathrm{g} / \mathrm{dl}$ ) in cases and controls respectively. Neither blood lead nor semen lead showed significant difference between cases and controls. There was significant positive correlation between blood lead and semen lead concentrations. There was no significant correlation of semen and blood lead concentrations with other semen parameters \& serum hormone concentrations (FSH, LH, \& Testosterone) in cases.

Conclusion: Though the association of blood or semen lead with male infertility was not established in our study, yet, increased seminal lead concentration found in our study subjects may be indicative of subtle exposure of lead in our environment. So, further study with larger sample size is needed. The clinicians should consider the lead measurements when evaluating male partners of couples with unexplained infertility and for assessment of lead status, semen lead measurement can be recommended.
\end{abstract}

Key words: Male infertility, blood lead, semen lead.

Introduction: Lead poisoning is one of the important occupational and environmental diseases in the world. Despite its recognized hazards, lead continues to have widespread commercial application. Though the incidence of serious overt lead poisoning is decreased due to diminished use of lead in gasoline and public health measures, there remains considerable concern over the effects of low level lead exposure. Lead may have adverse effects, - at lead concentrations once considered "normal" or "safe". Lead serves no useful purpose in the human body. ${ }^{1}$ Lead exerts multi-systemic toxic effects by inhibiting enzyme activity, (sometimes as a consequence of binding to sulfhydryl groups), interfering with the action of essential cations, (particularly $\mathrm{Ca}$, Iron and Zinc) and by altering the structure of cell membranes and receptors. ${ }^{1}$ Leaded petrol, lead pipes in household water supplies, newspaper, Xerox copies, cigarette smoking are sources of lead exposure. Battery repair, radiators repair, soldering, painting and printing are occupations prone to get lead poisoning. It is not biodegradable. ${ }^{2}$ Lead is a cumulative poison and accumulated in tissues over years. There is no 'safe' level in blood, although about $10 \mu \mathrm{g} / \mathrm{dl}$ can be tolerated. $>10 \mu \mathrm{g} / \mathrm{dl}$ in children $\&>25$ $\mu \mathrm{g} / \mathrm{dl}$ in adults may cause toxic manifestations. ${ }^{2}$ Pollution level of lead in Bangladesh are among the world's highest during dry season, falling during periods of medium and heavy rainfall \& the current blood level of lead concentration for adults in Dhaka city is about $50 \mu \mathrm{g} / \mathrm{dl}^{3}{ }^{3}$ Lead is a notorious reproductive toxin. Blood lead $>40 \mu \mathrm{g} / \mathrm{dl}$ have been associated with diminished or aberrant sperm production. ${ }^{1}$ Reports of declining human sperm concentration and male fertility have renewed interest about the role of environmental exposures in the etiology of human male infertility. The role of lead in male factor sub fertility is of particular current interest. ${ }^{4} \mathrm{WHO}$ estimates that there are 60-80 million infertile couple worldwide. ${ }^{5}$ About $40-50 \%$ of infertility is totally or in part due to a male factor. ${ }^{6}$ Unexplained infertility varies from $10-20 \%{ }^{7}$ Evaluation of male partner of infertile couples is to identify - potentially correctable conditions and treatment of which may improve the male's fertility. ${ }^{8}$ In order to fertilize an egg, a sperm has to bind with it. A sugar called mannose on the outer coating of the egg is crucial to binding. Mannose receptors located on the head of human sperm recognize the mannose on the coating of the egg and regulate the binding process. Then the sperm has to penetrate the egg. Successful binding induces an event called mannose induced acrosome reaction (MIAR) that help to release digestive enzymes from the sperm to ease its passage through the egg coating to its nucleus? To study the effects of lead upon the human male reproductive tract, a systematic analysis of lead levels \& correlation of it with other trace metals, semen parameters, sperm fertilization potential and biomarkers of human sperm function in men without occupational exposure to lead was done. Analysis of lead in seminal plasma as a biomarker to predict IVF success was performed examining parameters that could affect IVF outcome. The mean lead value was significantly higher. A significant negative relationship was detected between semen lead levels and the fertilization rate in IVF. Threshold 


\section{Study of blood}

value for semen lead was analyzed to be $42.29 \mu \mathrm{g} / \mathrm{dl}$. Threshold values for blood lead, $/ 40 \mu \mathrm{g} / \mathrm{dl} /$ above which the semen parameters are affected. Above this threshold value for the lead in semen, less than $63 \%$ of oocytes could be predicted to be fertilized. Below this threshold value of lead in semen more than $63 \%$ of oocytes could be predicted to be fertilized by IVF. So, simple measurement of semen lead level might be a useful addition in the evaluation of the male partner prior to an IVF attempt. ${ }^{4}$ Blood lead levels determined by the National Institute for Occupational safety and Health (1994) protocol, $>40.0 \mu \mathrm{g} / \mathrm{dl}$ require medical intervention. However, studies by several groups now suggest that lead intake levels even below this threshold are associated with a variety of adverse health effects in somatic tissues. ${ }^{10,11}$ Ascorbic acid supplementation $1000 \mathrm{mg}$ daily for 4 weeks may significantly reduce lead toxicity. ${ }^{12}$ Calcium deficiency potentially may result in elevated lead accumulation. Maintenance of adequate dietary calcium levels appeared extremely important toward minimizing susceptibility to lead toxicity. ${ }^{13}$ An alteration of Zinc and Copper homoeostasis is done by lead poisoning and Zinc and Copper supplementation may decrease the elevated lead levels. ${ }^{14}$

In Bangladesh no work has been done on lead status of general population of the country outside Dhaka city. Moreover no work has yet been done on infertile males of unexplained infertility. In this study, whole blood and semen lead concentrations were measured and correlated with fertility status. In our country IVF is now becoming popular for infertile couples but it is of huge cost with many unexplained failures. It is of great concern to find out the possible causes of the failures including the role of lead exposure. In this context, this study might be helpful for lead status evaluation and to find out its association with male infertility. Therapeutic intervention may be done by clinicians to decrease lead level and preventive measures may be taken nationally to reduce or eliminate even the low level lead exposure. Above all, by treating this reversible, treatable cause for infertility, some persons may procreate in natural ways without undergoing huge costly attempts of artificial methods of high technology.

\section{Materials and methods}

This case control study was carried out in the department of Biochemistry of Bangabandhu Sheikh Mujib Medical University (BSMMU), Shahbag, Dhaka, from January 2004 to December 2004. Informed written consent was taken from each study subject. 52 subjects were selected from the Centre for Assisted Reproduction, Shamoli, Dhaka. The subjects were male partners of infertile couples where there was no abnormality in female partners that may affect fertility. The subjects were divided into two groups: Group-I (Cases): 26 males with oligospermia and or asthenospermia, Group-II (Controls): 26 healthy age matched males with normospermia. Semen was collected in a previously treated metal free wide mouthed plastic container following three days abstinence. Semen analysis was done within 60 minutes after liquefaction of the semen. Blood samples of the subjects were collected (with EDTA for lead, without anticoagulant for hormone measurement). The serum was taken into microcentrifuge tube. The serum and whole blood with anticoagulant were preserved at $-35^{\circ} \mathrm{C}$. The clean supernatant of seminal fluid (after centrifugation) was taken into cryo-tubes and preserved at $-70^{\circ} \mathrm{C}$ till analysis was completed. Blood and semen lead concentration was measured by Graphite furnace atomic absorption spectrophotometry. Serum FSH \& LH were measured by-Abbott AxSYM system, based on MEIA principle and Serum Testosterone by ELISA. Semen analysis was done by ordinary light microscope using Makler chamber. All plastic wares including test tubes, semen collection cups, micro-centrifuge tubes, containers and pipettes were cleaned and made metal free, following a standard protocol. ${ }^{14}$ All statistical analysis was done by SPSS software package, 10.0 for windows. Values were presented as mean \pm SD and also as median. 95\% confidence limit was taken as level of significance. Mann Whitney U test was done to see the significant difference of blood and semen lead between the case and controls and Spearman's correlation test was done to see any significant correlation between the relevant values.

Results: Grouping of study subjects was shown in Table-I. No significant difference of age distribution was found between two groups. Table-II shows the serum FSH, LH \& Testosterone concentrations in cases and controls. No significant difference of serum hormones between cases and controls was found. Whole blood lead \& semen lead concentrations were compared between cases and controls by Mann-Whitney U test but no significant difference was observed (Table-III). Spearman's correlation test was done between whole blood lead concentration and semen lead concentrations in cases \& significant positive correlation was found $(\mathrm{P}<0.05)($ Table-1) \& $($ Fig- 1$)$.

Table I: Grouping of study subjects and age distribution

\begin{tabular}{|l|l|l|l|l|l|}
\hline Group & Number & Range & $\begin{array}{l}\text { Age(years) } \\
(\mathrm{mean} \pm \mathrm{SD})\end{array}$ & t-value & p-value \\
\hline $\begin{array}{l}\text { Group I-cases } \\
\text { (Oligos permic\&/or } \\
\text { Asthenospermic) }\end{array}$ & 26 & $27-45$ & $37.04 \pm 4.57$ & 0.643 & $>0.05$ \\
\cline { 1 - 1 } $\begin{array}{l}\text { Group II-controls } \\
\text { (Normospermic) }\end{array}$ & 26 & $26-45$ & $37.92 \pm 5.31$ & & \\
\hline
\end{tabular}




\section{Study of blood}

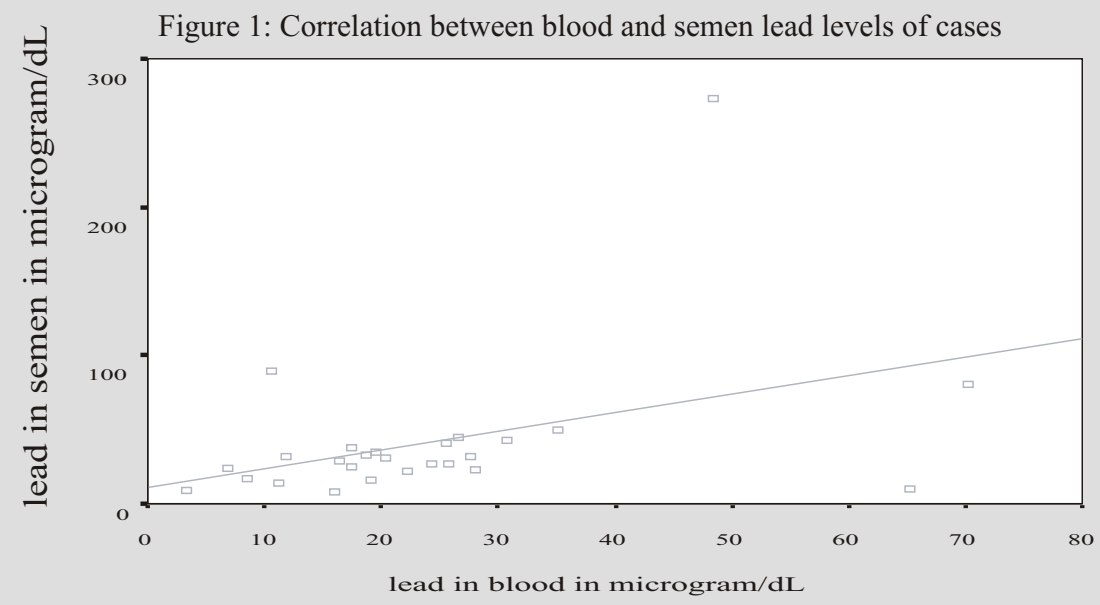

Spearman's correlation of blood and semen lead concentration with different semen parameters (semen volume, total count, motility and morphology of sperms) were performed. No significant correlation was found. Spearman's correlation of blood and semen lead concentrations with serum FSH, LH \& Testosterone concentrations were done, but no significant correlation was observed.

Table II: Comparison of Serum FSH, LH and Testosterone between cases and controls

\begin{tabular}{|l|l|l|l|l|}
\hline $\begin{array}{l}\text { Hormones } \\
\text { mean } \pm \text { SD }\end{array}$ & $\begin{array}{l}\text { Gr. }- \text { I (Case ) } \\
\mathrm{n}=26\end{array}$ & $\begin{array}{l}\text { Gr.-II (Control) } \\
\mathrm{n}=26\end{array}$ & t-value & -value \\
\hline FSH(mIU/mL) & $5.24 \pm 1.38$ & $5.35 \pm 1.43$ & 0.108 & $>0.05$ \\
\hline LH $(\mathrm{mIU} / \mathrm{mL})$ & $5.86 \pm 1.84$ & $6.62 \pm 2.09$ & 1.083 & $>0.05$ \\
\hline Testosterone $(\mathrm{ng} / \mathrm{mL})$ & $4.65 \pm 1.44$ & $5.40 \pm 1.92$ & 1.450 & $>0.05$ \\
\hline
\end{tabular}

Table III: Comparison of lead concentration between cases and controls

\begin{tabular}{|l|l|l|l|l|}
\hline $\begin{array}{l}\text { Variable(Lead) } \\
(\text { median })\end{array}$ & $\begin{array}{l}\text { Gr. I (Case) } \\
\mathrm{n}=26\end{array}$ & $\begin{array}{l}\text { Gr. II (Control) } \\
\mathrm{n}=26\end{array}$ & $\begin{array}{l}\text { Mann-Whitney U } \\
\text { value }\end{array}$ & $\mathrm{p}$-value \\
\hline Blood $(\mu \mathrm{g} / \mathrm{dl})$ & 19.96 & 17.68 & 271.00 & $>0.05$ \\
\hline Semen $(\mu \mathrm{g} / \mathrm{dl})$ & 29.56 & 28.17 & 331.00 & $>0.05$ \\
\hline
\end{tabular}

Discussion: The aim of this case-control study was to measure the lead level in Blood and Semen of infertile Bangladeshi males and to correlate these values with other semen parameters like semen volume, sperm count, motility and morphology to see any effect of lead on fertility.

The strategy of the study was to examine the interaction between two main variables: first, the degree of environmental exposure of lead \& second, the fertility status.
Blood lead level was used as a biologic index for recent exposure and semen lead level was used as an indicator for the direct exposure of reproductive tissue. Subtle changes in fertility status were evaluated through an assessment of semen parameters and reproductive hormones. Thus, chemical biomarkers of exposure (lead in blood and semen) were correlated with endocrinologic/biologic biomarkers (total testosterone, $\mathrm{LH} \& \mathrm{FSH}$ ) and semen parameters 


\section{Study of blood}

(volume, count, motility and abnormal forms). The median values of blood lead and semen lead concentrations were slightly higher in oligospermic population (cases) than in the normospermic (controls) but the difference was not significant. This finding was similar to El-Zohairy et al (1996). ${ }^{15}$ No difference of lead between cases and controls may be due to the fact that both were exposed to the same environment, none was occupationally exposed to lead. Serum FSH, LH \& Testosterone concentrations in cases and controls showed no significant difference (within normal reference ranges). The phenomenon of this normal hormone concentration in cases is very much implied because of the fact that $90 \%$ of sub fertile males are due to non-endocrine abnormalities $^{7}$ (Bhatla 2001). Significant positive correlation was observed between the lead concentration of whole blood and semen in cases. This finding is similar to Aribarg \& Sukcharoen (1996) ${ }^{16}$ and Benoff et al (2003). ${ }^{4}$ This might be due to any mechanism operating to transfer lead from blood to the male reproductive tract readily. This finding suggests that seminal lead concentration would be a useful biomarker for evaluation of male infertility.

Blood and semen lead concentrations showed no significant correlation with semen parameters. This is in contrast to Benoff et al (2003) ${ }^{4}$ who found weak negative correlations between seminal lead levels and semen parameters and stronger negative correlation between seminal lead values and sperm function tests like - mannose receptor expression and mannose-stimulated acrosome loss. The probable reason of our finding may be due to the fact that threshold levels for semen and blood lead concentrations were not exceeded above which semen parameters could be affected. Moreover, we did not perform sperm function tests which could be more informative in relation to effect of lead on semen parameters. No significant correlation of blood and semen lead concentrations with serum hormones (FSH, LH \& Testosterone) was observed. This is consistent to the finding of Benoff et al (2003) and Lancranjan et al (1975). ${ }^{17}$ This may be explained in light of low blood lead concentration of our population consequential of low environmental lead level that failed to affect hypothalamic pituitary testicular axis.

In our study, we could not prove the effect of environmental lead exposure on male infertility, yet we cannot deny the association of lead with male infertility because of some limitations of our study. Sample size was small. We used hot plate heating block for semen sample digestion. Use of microwave oven for semen sample digestion could improve detection of semen lead. Moreover, infertility in our study subjects might be due to some causes other than the lead exposure effect, like vitamins and trace elements deficiency and free radical assault etc. It is a matter of great concern to find out the causes of unexplained infertility. So, further broad based study with large sample size is needed to explore the association of lead status with male infertility in a more comprehensive and convincing manner.

\section{References}

1. Kosnett MJ, Katzung BG, editors. Heavy metal intoxication \& chelators: basic \& clinical pharmacology. Lange Medical Books: McGraw-Hill Medical Publishing Division; 2001.p.999-1002.

2. Vasudevan DM, Sreekumari S. Textbook of biochemistry (for medical students), 3rd ed. New Delhi: JAYPEE BROTHERS; 2001.p. 313-314.

3. Khaliquzzaman M. Bangladesh studies pollution levels. IAEA News briefs; $1996 ; 11(4): 73$.

4. Benoff S, Centola GM, Millan C, Napolitano B, Marmar JL, Hurley IR. Increased seminal plasma lead levels adversely affect the fertility potential of sperm in IVF. Human Reproduction. 2003;18(2):374-383.

5. BIRPERHT. Assessment of reproductive health care needs and review of services provided at the Levels of Thana, Union and Village. Dhaka Bangladesh: Institute of Research for Promotion of Essential \& Reproductive Health and Technologies; 1997.

6. Speroff L, Glass RH, Kase NG. Clinical gynecological endocrinology \& infertility. 6th ed. Lippincott Williams \& Wilkins; 1999. p. 1076-1096.

7. Bhatla N editor. Jeffcoate's principles of gynaecology. London: Arnold; 2001.p. 633-660.

8. Sharlip ID, Jarow JP, Belker AM, Lipshultz LI, Sigman M, Thomas AJ et al. Best practice policies for male infertility. Fertility and Sterility. 2002;77 (5):873-882.

9. US researchers find first conclusive evidence that lead is linked to male infertility [online, (February 2003)], ESHRE press release, available at: $<$ http:// www.eshre.com/ ecm/main.asp? Ian=99 \& typ = 301>

10. Miller GD, Massaro TF, Massaro EJ. Interactions between lead and essential elements: a review. Neuro Toxicology. 1990;1:99-120.

11. Xuezhi J, Youxin L, Yilan W. Studies of lead exposure on reproductive system: a review work in china. Biomedical and Environmental Sciences. 1992;5:266-275.

12. Dawson EB, Evans DR, Harris WA, Teter MC, McGanity WJ. The effect of ascorbic acid supplementation on blood lead levels of smokers. J Am Coll Nutr. 1999;18(2):166-70.

13. Aungst BJ, Fung HL. The effects of dietary calcium on lead absorption, distribution \& elimination kinetics in rats. Journal of Toxicology \& Environmental Health. 1985;16:147-159.

14. Tefas L, Ossian A, Ionut R, Bocsa H. The metabolism of some essential elements (copper and zinc) in experimental lead poisoning, [online, 1998], presented at INABIS.1998-5th Internet World Congress on Biomedical Sciences at McMaster University, Canada, Dec 7-16th. Available at: http:// www.mc master.ca/inabis 98/occupational/ tepas 0267/index.html [21/12/2004].

15. EL-Zohairy EA, Youssef AF, Naser SMA, Fahmy IM, Salem D, Kahil AK, Madkour MK. Reproductive hazards of lead exposure among urban egyptian men. Reproductive Toxicology. 1996;10(2):145-151.

16. Aribarg A, Sukcharoen N. Effects of occupational lead exposure on spermatogenesis. J Med Assoc Thai. 1996;79(2):91-95.

17. Lancranjan I, Popescu HI, Gavanescu O, Klepsch I, Serbanescu M. Reproductive ability of workmen occupationally exposed to lead. Arch Environ Health. 1975;30:396-401. 